\title{
Psoriatic onycho pachydermo periostitis (POPP)
}

\author{
Sarath Bethapudi • Jill Halstead • Zoe Ash • \\ Dennis McGonagle • Andrew J. Grainger
}

Published online: 11 July 2013

(C) European Union 2013

A 55-year-old female patient with a history of palmoplantar pustular psoriasis presented with a 12-month history of nail dystrophy that was followed by swelling and erythema of the right great toe for 6 months. She was otherwise well with normal baseline blood tests and chest X-ray. No improvement was evident with multiple courses of antibiotics.

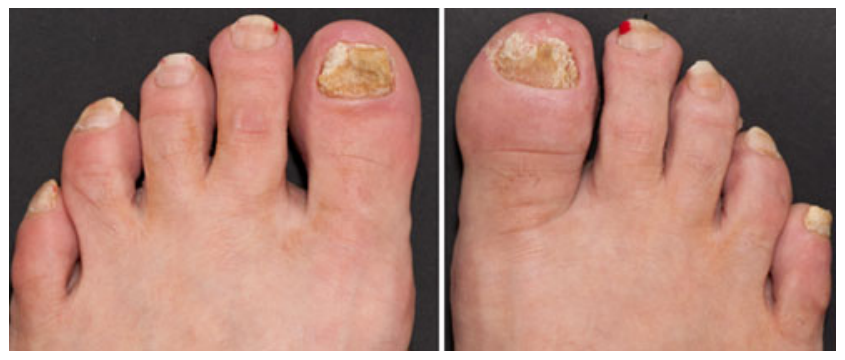

Fig. 1 Photographs of the right and left toes

The diagnosis can be found at doi: 10.1007/s00256-013-1682-8

S. Bethapudi · A. J. Grainger

Department of MSK Radiology,

Leeds Teaching Hospitals, Leeds, UK

J. Halstead · Z. Ash • D. McGonagle · A. J. Grainger

NIHR Leeds Musculoskeletal Biomedical Research Unit,

Leeds Teaching Hospitals, Leeds, UK

J. Halstead · Z. Ash · D. McGonagle

Leeds Institute of Rheumatic and Musculoskeletal Medicine,

University of Leeds, Leeds, UK

S. Bethapudi $(\bowtie)$

Leeds Teaching Hospitals NHS Trust, Chapel Allerton Hospital,

Chapeltown Road, Leeds LS7 4SA, West Yorkshire, UK

e-mail: bethapudi@gmail.com
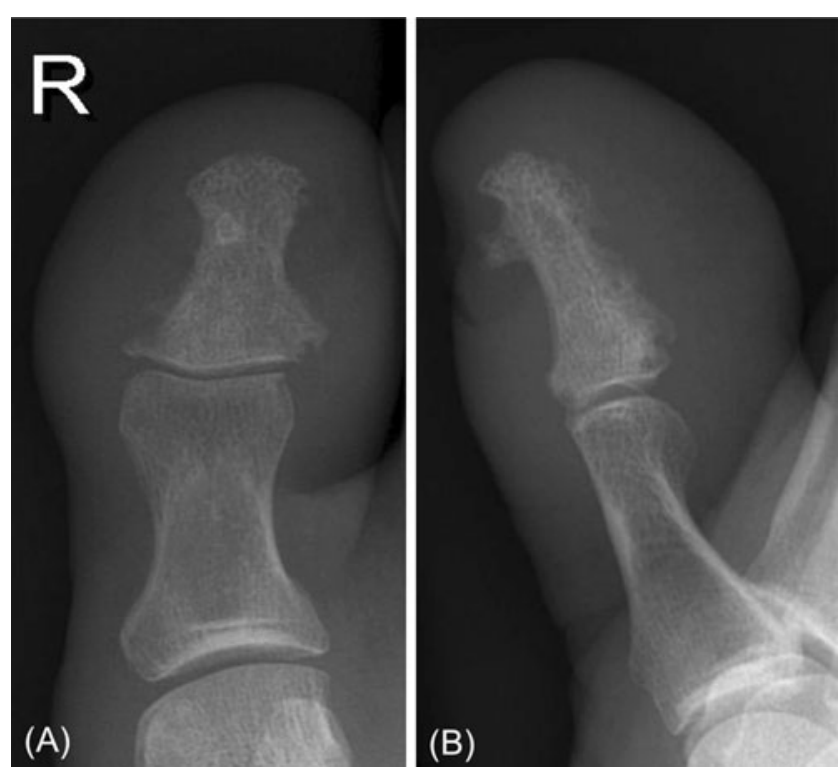

Fig. 2 Radiographs. a Frontal and $\mathbf{b}$ lateral
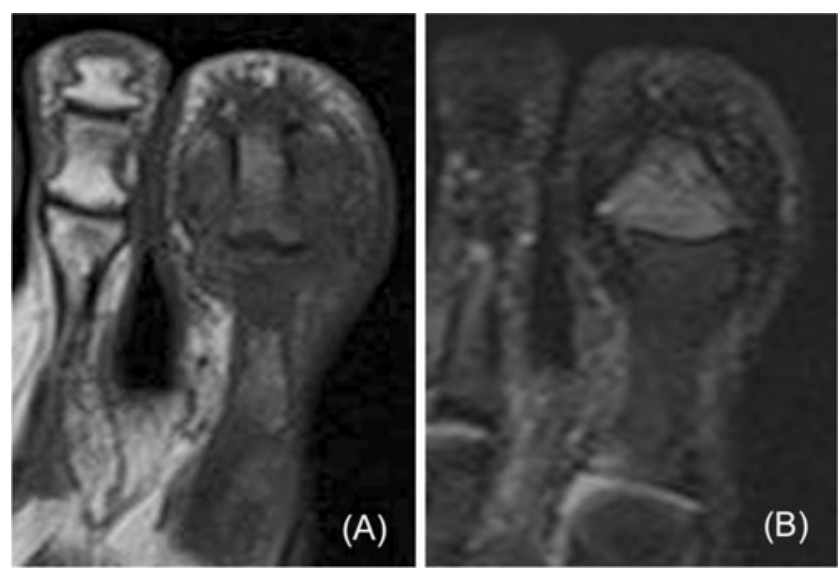

Fig. 3 a Coronal T1W and b coronal T2W fat-suppressed MRI 
Fig. 4 a Sagittal and $\mathbf{b}$ axial proton density MRI
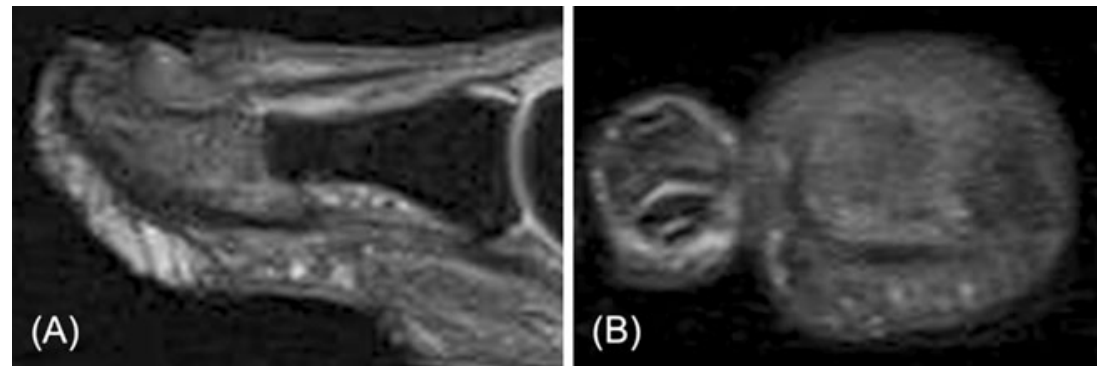

Photographs of both left and right toes are shown in Fig. 1. As part of the diagnostic evaluation she had radiographs (Fig. 2) and a subsequent MRI scan (Figs. 3, 4).
Disclosures Dr Andrew Grainger, Prof Dennis McGonagle and Dr Zoe Ash receive funding from the National Institute of Health Research, Leeds Musculoskeletal Biomedical Research Unit. Jill Halstead receives funding from Arthritis Research, UK. 